\title{
An Emancipation Paradigm through Critical Theory in Technology Education: An Action Learning Paradigm
}

\author{
Tomé Awshar, Mapotse \\ College of Education, Department of Science and Technology, \\ University of South Africa (UNISA), PO Box 392 Pretoria 0003 \\ mapotta@unisa.ac.za
}

\section{Doi:10.5901/mjss.2014.v5n3p502}

Abstract

This action learning study was conducted with senior phase technology education (TE) teachers in M5kg Circuit of Limpopo Province. In most cases action learning follows after participants have been through action research study even though some other scholars use this term interchangeably. The aim of this article is to report the progressive action undertaken by participants after they identified teachers' challenges in their classroom teaching practice. This was done so that appropriate action learning $(A L)$ intervention strategies could be embarked upon to emancipate other technology education teachers who were not participating on action research study. A reconnaissance study as the first cycle stage of AL was instrumental in identifying the teachers' challenges and that was followed by the main action research (AR) study. Focus group, workshop/seminars and audio-visual photos were employed in gathering data from the teachers of twelve (12) schools in M5kg Circuit secondary schools. The findings revealed teachers' incapacity in terms of their knowledge and teaching of technology in the areas of technology-specific teaching experience, technology lesson planning, technology assessment, level of internal and external support for technology teaching, resources for technology teaching and learning, technology curriculum policy interpretation and implementation, and teacher-learner ratio in a technology class. In responding to the findings, the results prompt the development of the guidance to emancipate un- and under qualified technology teachers to confidently teach technology. Critical theory was used to underpin the study while AL was instrumental as the methodology to empower and equip teachers to teach without any formal training of technology education as these was evident from their interview responses.

Keywords: Action Learning Paradigm; Technology Education; Critical Theory

\section{Introduction and Motivation of the Study}

South Africa has for many years struggled to deliver an acceptable mathematics, science and technology education at primary and high school (Gauteng Department of Education, 2010). Poor learner performance in South Africa has been attributed to different issues such as learners' social and economic circumstances, lack of learner support materials and related resources, overcrowding, and a lack of teacher and learner discipline and commitment, to mention but a few (Mahomed, 2004; Mapotse 2012). Some education stakeholders hold assumptions that students perform better when their teachers have received quality education and training in the subjects they teach and at the levels/phases in which they are placed. To address some of the challenges technology education teachers' faces in their delivery of technology pedagogy and content knowledge an action learning paradigm was sought. Action learning is a process which involves working on real challenges, using the knowledge and skills of a small group of people combined with skilled questioning, to re-interpret old and familiar concepts and produce fresh ideas (Action Learning Associates, 2014).

Quirke (2014) avers that action learning is the coordinated focus on professional development by the participants themselves. The participants will form groups to research a similar problem, concern or interest. The problems, around which these collaborative learning groups are formed, are taken directly from the participants' daily working lives; in our case that is the classroom. These action learning groups then look at a variety of ways in which that problem can be solved and try out, actively, each approach. Amongst the multiple challenges that can be mentioned, teacher development and empowerment become prominent as it is technology teachers that are placed at the forefront to teach learners this relatively new subject. These TE teachers are lumped with other subjects as compared with the rest of other teachers and their situation was even worse by the rolling out of the outcomes-based Curriculum 2005(C2005) in 1998. The new curriculum posed new demand for these TE teachers. The majority of in-service teachers found this initial change to outcomes-based education (OBE) and the introduction of C2005 to be very complicated, confusing and 
demoralising with lots of new terminology and content to be learned (De Jager, 2011). To try to make the curriculum understandable, more changes followed in 2002 after the review of C2005 in 2000. The reviewed C2005 was renamed National Curriculum Statement (NCS). This review was followed by yet another review in 2009 with its implementation planned to commence in 2010. This review produced the Curriculum and Assessment Policy Statement (CAPS). The NCS remains as a policy, while the new CAPS is an attempt to give clear guidelines for the implementation of the NCS (Curriculum News, 2010; De Jager, 2011; Motshekga, 2013 \& 2014). This confirms the challenge that teachers face regarding their understanding of the curriculum; expressed in terms of constraints that they face about its implementation. Specifically, technology since it requires skilled teachers due to its nature particularly as a theorypractice based subject. However, it is distressing to disclose that $99 \%$ of the teachers teaching technology have no qualification to teach technology (DoE Gauteng Memo 202, 2004). The situation seems worse in Limpopo Province, which is among provinces known to be underperforming.

Some scholars in the technology field have engaged in research targeting variety of aspects of technology education (TE), for instance Elliot (1991); Freeman (1998); Schafër (1999); Edge (2001); Potgieter (2004); Hoban (2005); Pudi (2007); Mapotse (2012); Kufaine \& Nyirenda (2013) and Yager (2013). The afore mentioned scholars belonging to both national and global villages have used some common instruments or similar approaches to gather their data and little has been done in using action learning approach to emancipate teachers through technology pedagogy content knowledge. With this study I want to attempt to fill that gap by sharing experiences gained through action learning process with TE teachers of selected schools from Limpopo Province. I will be sharing those technology teachers' experiences as a critical realist using action learning paradigm and also underpinning this study through critical theory.

\section{Critical Theoretical Framework}

Theory helps in the researcher's thought and in making research decisions and sense of the world around. Theory is also an explanation that discusses how a phenomenon operates and why it operates as it does and it serves the purpose of making sense out of current knowledge by integrating and summarizing this knowledge, and thus it can be used to guide research by making predictions (Johnson \& Christensen, 2004). Critical theory was first defined by Max Horkheimer of the Frankfurt School of sociology in his 1937 essay Traditional and critical theory (Tooley, 2000). The effort to conceptualize critical theory relied on the writings of Karl Marx (Tooley, 2000). Its basic purpose was emancipation and self-determination.

My choice of critical theory was motivated by my intent to emancipate the technology teachers in terms of overcoming the challenges that they faced in their knowledge and teaching of the subject. By reflecting critically on their unfavourable status-quo, technology teachers could be helped to think about how they could free themselves from such unfavourable conditions and take action about it - so to be emancipated. The kind of intervention in such involvement is facilitative rather than instructive, so that those being helped can later be self-reliant and become independent to address their situation. Specifically, the next section explains how critical theory found relevance in this study.

\subsection{The significance of critical theory in this study}

In the context of this study, critical theory is a social theory oriented towards critiquing and changing technology teachers' circumstances, i.e. their limited technological knowledge and how to teach it. This study would hopefully create enough awareness in these teachers to be able to pass judgment on their teaching of technology and to evaluate their knowledge base of technology with the sole purpose of being emancipated from this situation. Thus, for purposes of this study, critical theory was used to exploit the literature in the field of technology education (Creswell, 2014).

Critical theory indicates that a fundamental dialectical relationship between theory and practice are indivisible (Tooley, 2000), especially in technology. This aligns well with our understanding of technology education, that it is fundamentally a hands-on enterprise. Hands-on in technology must be taken to refer to learning through experiences, that is, through practical engagement in investigating, designing, making, evaluating and communicating ideas and plans (DoE, 2003). Approaching it theoretically is unfathomable.

Its core content and themes stress that the outcome should be a product, artifact, model, ornament, or new systems or processes. Applied in this study, we expected that from a critical theoretical perspective, the ultimate action research intervention would emancipate the Grades 8 and 9 technology teachers in selected schools of the Limpopo Province from their challenges as stated above. Hence, we assumed that engaging teachers in critical theory had the potential to improve their understanding about the knowledge and pedagogy of technology within their context. The next 
section explains how I became aware of the problem.

\subsection{Becoming aware of the problem}

I became aware of the problem as a lecturer at the University of Limpopo before I joined Unisa. I lectured pre-service student teachers enrolled for the Bachelor of Education in technology education. During the evaluation of the student teachers' practice teaching I observed a lack of knowledge in the teaching of technology by veteran teachers in the field. This lack of knowledge manifested in:

- The analysis and interpretation of technology curriculum policy document. Planning of the learning programme, work schedule and lesson.

- Absence of creativity in utilizing the material resources available in the local context Student teachers seemed more knowledgeable in their subject of technology compared to their assigned mentor teachers as they were assisting their mentors in this creative process.

- The student teachers ended up exchanging roles with their mentors to mentor them (mentors) because their situation posed such demand. This intervention confirms the DoE's (2003) declaration:

Whilst educators in South African schools are qualified to teach a variety of subjects, many of the educators of technology are uncomfortable with the pedagogy of technology.

I argue that teachers can implement technology with confidence and every chance of success within their context only if they can be guided how. The starting point is to identify the areas of challenges through reconnaissance study as a part of the first cycle of action research then roll out the action research once the themes are identified. The participants (technology teachers from five sampled schools) and I employed AR circular and spiral activities to resolve challenges as themes. The participants, from henceforth they will be addressed as technology facilitating team (TFT), grouped themselves to engage their colleagues from other twelve (12) schools with action learning.

\section{Action Learning Design and Methods}

This is an action learning (AL) study. I monitored the process at the distance and direct the TFT what to cover during their presentations. Quirke (2014) highlight the goals of action learning as follows:-

- to encourage best practice in the classroom and enhance the quality of learning for the students.

- to develop effective PD (Professional and Personal Development) programs within the institution by encouraging all instructors to get involved in Action Learning projects.

- to develop a self-managing PD program which operates under the control of the instructors themselves.

- to encourage instructors across the institution to work together more closely in sharing and applying their knowledge and experience.

- to encourage instructors to define the various issues and problems that they encounter in the workplace and to address them through a process of Action Research. to encourage and support instructors in future proposals, publications and conference papers.

- to initiate a cycle of Quality Improvement.

It was hoped that both the novice and experienced teachers involved in this AL study would be empowered to teach technology irrespective of their contextual setting. The study would contribute significantly to action research studies in the field of technology education.

The initial five sampled schools of technology teachers' characteristics included: they all faced some challenges in the teaching of technology; for convenience in organising the groups, the schools were a reasonable distance from one another within one circuit, districts, regions and province; only Grade 8 and 9 technology teachers in the same senior phase were selected; all these teachers taught technology. These teachers were emancipated during AR main study. They further grouped themselves to forms technology facilitating team (TFT). This TFT together with the technology district drafted a yearly programme to develop and empower other twelve (12) secondary technology teachers' within the same circuit. This is the beauty of $A R$, it yield $A L$ and the participants can run AL independently from the AR practioner.

A variety of data collection techniques were incorporated on this AL paradigm. According to Wadsworth (cited in Maree, 2010), multiple methods help the researcher to overtly seek different kinds of views and perspectives from data sources. Focus group, workshop, seminars and audio-visual photos were employed in gathering data from the teachers 
of twelve (12) schools in M5kg Circuit secondary schools of Limpopo Province. Multiple methods also helped me to overcome the bias that could otherwise result from the use of a single method. Focus group, workshop/ seminars and audio-visual photos were employed in gathering data from the teachers of twelve (12) schools in M5kg Circuit secondary schools. Obtrusive and unobtrusive varieties of research techniques used for professional development purposes during AL study are briefly explained according to Kemmis \& McTaggart (1988) and Wicks \& Reason (2009) as follows:

- Focus group: I advised the TFT to split participants into manageable groups for an interview purposes and efficient utilization of time. As this type may be structured questions, as with the questionnaires, or unstructured, with the respondent given free rein to discuss ideas or opinions to prompt. It can be conducted face-to-face, via the Internet or through telephone conversations. It was conducted face-to-face in an unstructured manner.

- Workshop/Seminars: Cycle plans and activities thereof were jointly and fully discussed during meetings. During the contact sessions the TFT and participants ran several workshops around the theme or core content area of interest. A work schedule from the district was followed to the latter.

- Use of video and audio records: A researcher uses a video camera and audio technology to record the actual events related to the research problem in the setting. Photographs make useful reference points for subsequent interviews and discussion of the data. I used both digital still cameras for photo-capturing and digital audiovisual for recording teachers' workshops or seminars, as well as some of the meetings with the whole group (TFT and participants). This was carried out for later review and analysis.

The TFT spent some afternoon at the agreed upon common venue empowering their technology colleagues within the circuit. They split the topics on the yearly work schedule based on their expertise under the guidance of the district facilitator.

\section{Findings}

The difference between AR and AL is that in AL no strict pattern of cyclical process of sages to follow, the facilitators can start their process anywhere. The following were observed from the group as AL facilitators roll out AL activities with the M5kg Circuit AR participants together with district subject advisor and me as AR practitioner. follows:-

Imperatives growth points from the teachers' perspectives due to being part of AL group can be summarized as

* Participants were able to contextualize their teaching and use readily available resources from their local setting;

* Participants gained insights into new approaches to previously challenging topics of technology education, e.g. system and control;

* Participants managed to increased learners concentration and motivation since their creativity was expressed on their AL projects;

* The participants were able to implement technology policy, improved their delivery skills as well as teach their learners with confidence and every chance of success.

The AL participants experience major benefits as individuals and their growth was evident in the following area:-

* Facilitation and presentation skills improved as they interacted with their colleagues by sharing the topics of their expertise;

* Individual technology teachers improved their technological skills, technological knowledge and values in handling diverse learner population;

* The AL individual participants improved their classroom practice in both pedagogy and didactic;

* A sigh of relieve was expressed as greater understanding and awareness of some technology areas and or topics were unpacked in details. The practice was that in most instances topics like graphic drawings, electronics and mechanical systems were overlooked at until AL series.

\section{Discusion of Integrated Data from Three Data Sources}

Data analysis followed a thematic and narrative form. Themes that emerged from the analysis of the three data types (focus group, workshop/seminars and audio-visual photos) guided the presentation of findings. This process of data analysis focused on understanding the teaching and learning actions and events within the participants' settings and contexts. Findings from the audio-visual photos served as an umbrella for the focus group interviews and workshops or 
seminars. Findings from the focus group and seminars sought clarity of the audio-visual photos. Thus photos interrogations were followed by focus group and the seminar during data gathering. Thus, data from these sources were analysed holistically.

The themes were selected to cover aspects of technology teaching from policy interpretation to classroom practice. These themes include technology-specific teaching experience, technology lesson planning, technology assessment, level of internal and external support for technology teaching, resources for technology teaching and learning, technology curriculum policy interpretation and implementation, and teacher-learner ratio in a technology class.

\subsection{Technology-specific teaching experience}

Many teachers of technology were asked to volunteer to teach technology. As a result many do not have any qualifications in technology education. Some may be experienced in other subjects because they were already qualified in those subjects when they were asked to cross over into technology. Hence, many of them may be qualified in other subjects but not specifically in technology education. Given this background, technology teachers held reasons for teaching technology which ranged from being coerced into teaching it to basically having the passion for it. For instance, the interviews revealed two teachers stating:

It was just allocated to me.

It's fun, interesting and compels one to be innovative.

Bearing in mind this situation, most of technology teachers are generally uncomfortable with the pedagogy of technology as it was revealed from the interviews. Some did not even have any interest in teaching technology as one contended:

It just came along while I am already teaching and I didn't develop any interest in the subject.

It can be gathered from the teachers' responses, that they were not grounded in the learning area of technology. By implication this suggests that they had challenges planning the technology lessons.

\subsection{Technology lesson planning}

Teachers' responses in the workshop interaction revealed that quite a number of technology teachers within M5kg indicated the importance of using both the textbook and the curriculum policy document for their lesson planning. However, it surfaced from the interviews that teachers prioritised the use of a textbook as some indicated:

If educators were provided with at least a textbook so that we are able to prepare our learning programme.

I don't think the challenges I meet as stated would have happened if I had relevant and enough textbooks for learners.

We need enough textbooks and learner support material.

It would appear that teachers expected to be supplied with a plan so that all that they need to do is to get into class and teacher, without having to start by working hard developing lesson plans:

We want to be supplied with pacesetters, scheme of work and draft lesson plans.

This was confirmed when we requested teachers' lesson plans so that we could follow their teaching properly during the observations. Many could not produce them. This could only mean two things: either they did not prepare any lesson plans, or they were uncomfortable to disclose them to us out of lack of confidence that they planned correctly. Only two out of five schools' teachers could produce their lesson plans.

\subsection{Technology assessment}

Assessment should ideally be integrated with planning so that teaching and learning activities are not devoid of it. An interview question sought to establish the assessment methods that technology teachers applied during their teaching. One teacher responded by not really giving the answer that I sought in this regard: 
We are assessing skills, knowledge, attitude and values. We evaluate learners' performance.

However, some of the teachers mentioned the assessment strategies that they applied in their technology class assignments, class work, homework, tests and examinations. In the questionnaire teachers were asked to indicate if they planned any technology design projects or any tasks (capability, case study or resource tasks) for their learners. They did not check this aspect in the question. One teacher blamed lack of support by the school on this matter:

Technology at our school is not taken into consideration because learners are not doing any practical work.

This is quite unfortunate because teaching of technology mainly follows a design project approach in the context of problem solving. Only three teachers indicated in the interviews that they had a copy of provincial or national assessment manuals. This confirms their lack of capacity and support in terms of assessment in technology.

\subsection{Level of internal and external support}

Technology, being relatively new in the curriculum, may not thrive without a concerted commitment to empowering technology teachers. Teachers were keen to see support both from within and outside their schools to help them develop in the knowledge and teaching of technology. They expressed this need as follows during the interviews:

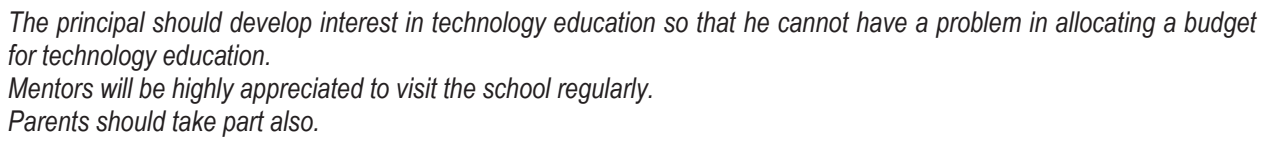

The teachers urged their School Management Teams to take technology seriously and to allocate its budget and teachers accordingly. The responses from the seminars indicated that support received from district office was very weak compared to support received from their colleagues and School Management Teams. The expressed lack of support from the district was attributed to the fact that the district had not yet appointed a district-based subject advisor for technology education.

Lack of support was also experienced in terms of provision of resources as can be seen from the next set of findings.

\subsection{Resources for technology teaching and learning}

It was observed that there was a lack of textbooks for both teachers and learners. In some schools there was not more than one textbook among the learners. Some teachers in the same schools were sharing a textbook. This state of affairs was confirmed from the findings from the interviews as expressed by respondents:

\section{We don't have enough resources. \\ I guess it's a hands-on subject and there are no resources are available. \\ Learners should be encouraged to buy necessary resources if needed.}

The teachers sampled pleaded for Department of Education Limpopo Province and their schools to provide the necessary resources - resources for learner group projects, a workshop centre where learners can do technology handson, technology materials to expose and orientate learners on, and a technology resource centre.

I gather in all the selected schools that there were no technology-specific rooms where learners could engage in practical and making activities or projects.

\subsection{Technology curriculum policy interpretation and implementation}

It was evident from all data sources that there was a great need for teachers to have access to the technology curriculum document in the first place, and to be helped to interpret and implement it. One teacher remarked in this regard:

I don't think the challenges I meet as stated would have happened should I have had the technology curriculum policy document as a guide. 
I requested the teachers to see the curriculum policy documents that they used. No one had any across all the sampled schools. A few of them offered the excuse that they had the documents but could not locate them at that stage. A few responses in the interviews on this aspect, which were confirmed by how the teachers responded to the questionnaire, were that they did not have them; that even if they had them they could not interpret or implement them. Here are the accounts of three of them:

I don't know the learning outcomes.

We don't have the policy documents at our school.

I don't know the learning outcomes by heart; I have to refer to the curriculum policy document.

\subsection{Teacher-learner ratio in a technology class}

Unmanageable learner numbers in a technology class render the teaching of technology ineffective. This becomes an added constraint that technology teachers are faced with. We observed that teachers' movement in the classroom during their lessons, and their interaction with learners was extremely limited due to overcrowding. It was difficult to have a chair or even a space to sit down. The teacher-learner ratio ranged from 1:60 to 1:90. This proved to impact on a few things, for example even though the schools had a monthly schedule for tests, the interview findings indicated that the turnaround time for marking learners' written tests took between two and three weeks. Marking overlapped into the next test dates. One teacher expressed his concern in this regard:

The department needs to improve the teacher-learner ratio so that an educator is faced with a manageable class.

\section{Linking Action Research with Action Learning}

Hoban (2005) stated that "teaching is more complex than it has ever been before. We need teachers who are reflective, flexible, technology literate, knowledgeable, imaginative, resourceful, enthusiastic, team players and who are conscious of student differences and ways of learning". It can be possible to produce such a teacher through AL, and as Cohen \& Manion (1994) pin point in this regard that action research is a small-scale intervention in the functioning of a real world and a close examination of the effects of such intervention. With a sample of technology teachers from selected schools in Limpopo Province, I made some interventions and monitored their efficacy through the AL project per cycles.

Action Learning Phase 2, as depicted in Figure 1 below, is the phase that follows Reconnaissance Phase 1 of AR. This Reconnaissance Phase 1 is a minor phase of the study for fact-finding purposes. AR Phase 2 was implemented to address Phase 1 identified challenges as themes. It was this AR Phase 2 which served as a catalyst to shape the study further. The AR Phase 2 confirmed that the participants are ready to engage their colleagues with AL as Phase 3 of the study. The AR Phase 2 laid a solid foundation for further inquiry to unfold the main AL Phase 3.

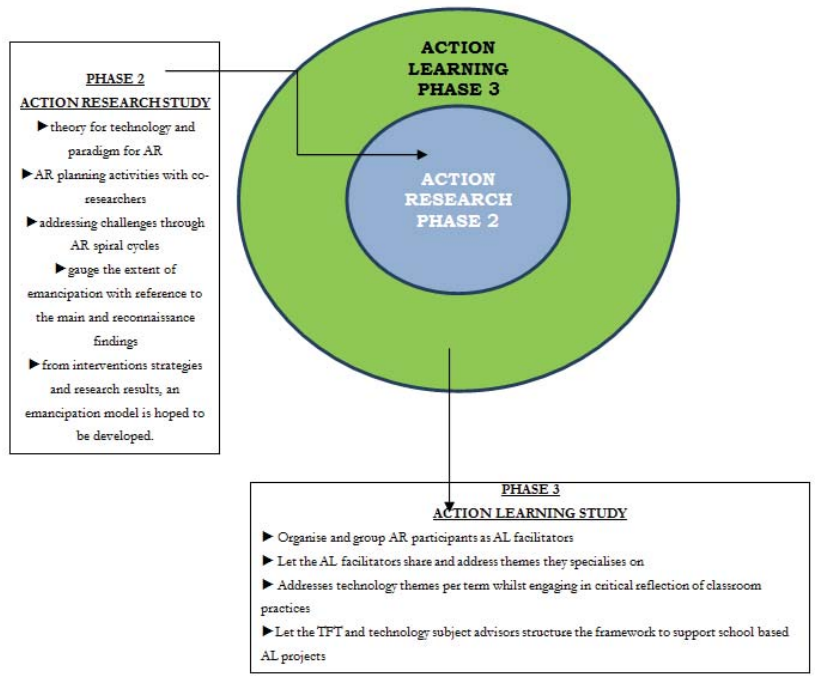

Figure 1: Action Research as Phase 2 and Action Learning as Phase 3 of the study 
Combining collaborative structure with action learning process is an effective way of providing high levels of support and guide for action learners as they design their own action and engage in the process of studying the outcomes (Riel, 2010). The guidelines to engage in target population discrimination before emancipation are reflected below.

The guidelines have been inspired by the teachers' reflection at the end of each AL project cycle during Phase 3 of this AL. This confirms Douglas statement, which stresses that "all education is continuous dialogue - question and answer that pursue every problem to the horizon", and the action learner facilitator should apply the guidelines in the following manner (this is just a guide, one is free to start anywhere):

- As a facilitator start a knowledge building dialogue with the participants based on the assumptions you hold about the study;

- Take into consideration that the participants are a community of diverse individuals from different backgrounds;

- Come up with mini projects within a bigger project and distribute leadership within the members and hold the group responsible and accountable on deliverables;

- The facilitator should carry out research work in learning circles - that is a structure for organizing group interaction within a set of guidelines to encourage individual ownership of the project; and

- Both the ethical norms and expectations during the AL journey should be spelled out and highlight the learning circle product as it can be used as a stepping stone towards the final research product.

Since technology is one of the subjects that falls among some scarce skill, it was appropriate to engage senior phase technology teachers with a collaborative action learning study as an effective way to provide high levels of support in both teaching and learning of technology.

\section{Conclusion and Recommendation}

This study was set out to identify the gaps that the senior phase technology teachers at M5kg Circuit of Limpopo Province faced regarding their knowledge and teaching of technology. There was a definite problem regarding the interpretation of the technology curriculum policy document, programme, schedule and lesson planning, and lack of taking advantage of the available resources. These challenges were identified during the Reconnaissance study as Phase 1 stage of this AR study. This problem was magnified by other related problems that were revealed by the findings, for instance, lack of internal and external support and what seemed an unmanageable teacher-learner ratio. Hence, by implication this indicated the need for AR Phase 2 intervention in the challenges that technology teachers faced. The findings of the AR Phase 2 confirmed the research problem and assumptions that I had. Thus, the next step was to continue with Phase 3, the Action Learning study, to intervene in the broader scale challenges that the teachers faced as a way of addressing the research problem within the whole circuit.

The phases of the study are structured as follows:-

* Phase 1 was Action Research Reconnaissance study for fact finding purposes;

* Phase 2 was Action Research Main study to address the challenges identified during Phase 1 and those challenges were then turned into themes;

* Phase 3 was Action Learning study, to provide space for the emancipated first group of participants to serve as AR facilitators to their colleagues within the same circuit. These technology facilitating team (TFT) together with the district subject advisor impacted their circuit colleagues;

* Envisaged Phase 4 will be Action Learning Community Engagement Project were AL cluster committees will be established to serve as a support base for the schools that are adjacent to each other.

The above is supported by Edge (2001), who draws on Altricher, Posch \& Bailey. (1993) and points out that the purpose of Action Research

"is not simply to describe, interpret, analyse and theorize - the stuff of traditional research - but to act in and on a situation to make things better than they were."

Therefore I end up by interpreting Action Learning as a process that follows after a researcher has concluded the Action Research study with the intention of implementing framework(s), model(s) or guidelines developed during the Action Research process. Action Learning is one step further of Action Research as supported by this statement: "The end of learning is action, not knowledge" from Peter Honey. 


\section{References}

Action Learning Associates. 2014. What is Action Learning? Online accessed on 18 January 2014 from: http://www.actionlearningassociates.co.uk/actionlearning.php.

Altrichter, H., Posch, P. \& Somekh, B. (1993). Teachers investigate their work: an introduction to the methods of action research. London: Routledge.

Cohen, K. \& Manion, L. 1994. Research Methods in Education (4th ed.). London: Routledge.

Cohen, L., Manion, L. \& Morrison, K. .2000. Research methods in education. London: Routledge.

Creswell, J. W. 2014. Research Design: Qualitative, Quantitative, \& Mixed Methods Approaches (4th ed.). London: SAGE.

De Jager, R. (011. Latest changes in the technology education curriculum in South Africa. Paper presented PATT25: CRIPT 8 Conference in June in London.

Department of Education. 2001. Policy document: Technology intervention, Curriculum 2005 Grades 5 \& 9. Pretoria: Government Printers.

Department of Education. (2003). Revised National Curriculum Statement Grades R-9 (Schools): Teacher's guide for developing learning programmes Technology. Pretoria: Government Printers.

Department of Education. 2004. Revised National Curriculum Statement Grades 7-9 (Schools). Pretoria: Government Printers.

De Vos, A.S., Strydom, H., Fouche, C.S. \& Delport, L.S.L. 2002. Research at grass roots (2nd Ed.). Pretoria: Van Schaik.

Edge, J. (ed.) 2001. Action research: case studies in TESOL practice. Alexandria, VA: TESOL Inc.

Elliott, J. 1991. Action research for educational change. Milton Keynes, UK: Open University Press.

Ferrance, E. 2000. Action research. Virgin Island: Brown University.

Freeman, D. 1998 Doing teacher research: from inquiry to understanding. Boston: Heinle \& Heinle.

Gauteng Department of Education (GDE). 2010. Gauteng Mathematics, Science and Technology Education improvement strategy: 2009 - 2014. January 2010. Johannesburg: GDE.

Gay, L.R. 1987. Educational research: Competencies for analysis and application (3rd Ed.). Columbus: Merrill.

Hartley, R (Ed). 2011. Education Handbook: Connecting to make a difference. Stellenbosch: Argo.

Hoban, G.F. (Ed). 2005. Developing a Multi-Linked Conceptual Framework for Teacher Education Design. The Missing Links in Teacher Education Design, (1-17).

Hofstee, E. 2006. Constructing a good dissertation: A practical guide to finishing a Master's, MBA or PHD on schedule. Sandton: EPE. Johnson, B. \& Christensen, L. 2004. Educational research: Quantitative, qualitative and mixed approaches (2nd Ed.). Boston: Pearson. Kemmis, S. \& McTaggart, R. (eds.). 1988. The action research planner. Victoria: Deakin University.

Kufaine, N. \& Nyirenda, L. 2013. Science and Technology function literacy: case of Malawi. In Southern African Association for Research in Mathematics, Science and Technology Education (SAARMSTE). Proceeding of the 21st Annual meeting on "Making Mathematics, Science \& Technology Education - socially and culturally relevant in Africa". South Africa, University of Western Cape, Cape Province, $14-17$ January.

Mahomed, H. 2004. Challenges in Curriculum Transformation in South Africa. Paper presented at the $5^{\text {th }}$ Annual Speaking Conference $15^{\text {th }}$ - 18 th May 2004, Birchwood Hotel Boksburg, Gauteng, South Africa.

Mapotse, T.A. 2012. The teaching practice of senior phase Technology Education teachers in selected schools of Limpopo Province: an Action Research study. University of South Africa (D.Ed. Thesis).

Maree, K. \& Pietersen, J. 2010. "Sampling". In Maree, K. (Ed.), First steps in research. Pretoria: Van Schaik.

Mauer, K.E. 1996. Formulating proposal for theoretical and qualitative research. Johannesburg: RAU Press.

McMillan, J.H. \& Schumacher, S. (1989). Research in education: A conceptual introduction (2nd Ed.). London: HarperCollins.

McNiff, J. 1988. Action research: Principles and practice. New York: Macmillan Education Ltd.

Memorandum No. 202. 2004. Technology Workshops. Gauteng: Government Printers.

Mertens, D.M. 1998. Research in education and psychology. London: Sage Publications.

Moeng, K. B. 2009. Developing leaders for the future. DoE - Senior Education Specialist for Technology in Gauteng West District. Guest Speaker at Pretoria regional conference of Technology Association South Africa in 2009. Pretoria Technology Conference, 23 May 2009, Rietondale Primary School.

Motshekga, A. 2013. Basic Minister of Basic Education presenting a guest lecturer at University of South Africa. Curriculum Reform and Transformation Conference. Theme: "Realities, Possibilities and Uncertainties". 16-17 October 2013, Unisa, Kgorong, Pretoria, Gauteng Province, South Africa.

Motshekga, A. 2014. Basic Minister of Education presenting Grade 12 matric results at Monte Casino, under the auspices of SABC 2 Channel on the 07th January 2014, Johannesburg, Gauteng Province, and South Africa.

Nampota, D. Thompson, J \& Wikeley, F 2009. The development of human capacity in Malawi: The role of 'science and technology'. International Review of Education: Vol. 55, pp 59 - 74

Potgieter, C. 2004. The impact of the implementation of technology education on in-service teacher education in South Africa. International Journal of Technology and Design Education, (14): 205-218.

Pudi, T.I. 2007. Understanding technology education form South African perspective. Pretoria: Van Schaik.

Quirke, P. 2014. Action Learning - philselsupport. Accessed on: 18 January 2014. Online at: http://www.philseflsupport.com/actionlearning.htm.

Reason, P. \& Bradbury, H. 2001. The SAGE handbook of action research: Participative inquiry and practice (1st Ed.). London: Sage. 
Riel, M. 2010. Understanding Action Research, Centre for Collaborative Action Research. Pepperdine University .Accessed on: 20 October 2010. Available at: http://cadres.pepperdine.edu/ccar/define.html .

Schafër, M. 1999. Designing and making a difference: An exploration of technology education for rural school teachers. MEd dissertation. Cape Town: Rhodes University.

Tooley, W. R. 2000. Political rationality \& government mechanisms: Maori education policy in the new millennium. MA in Education dissertation. Auckland: University of Auckland.

Wicks, P.G. \& Reason, P. 2009. Initiating action research: Challenges and paradoxes of opening communicative space. SAGE (Online). Accessed on: 7 January 2014. Available at: http://arj.sagepub.com/cgi/content/abstract/7/3/243 .

Yager, R.E. 2013. Successes and continuing challenges: Implementing the changes in professional development for teachers in the U.S. International Journal of Education in Mathematics, Science and Technology, 1(3), 184 - 189. 